
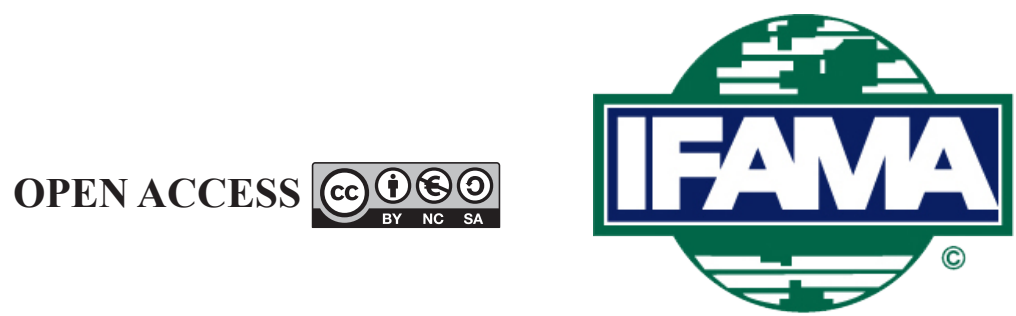

International Food and Agribusiness Management Review

Volume 23, Issue 3, 2020; DOI: 10.22434/IFAMR2019.0115

Received: 29 July 2019 / Accepted: 2 March 2020

\title{
Border effect of agricultural trade between China and the Belt and Road countries: a computable general equilibrium model analysis
}

\author{
RESEARCH ARTICLE \\ Jingqi Dang ${ }^{\circledR a}$ and Yipu Pang ${ }^{\mathrm{b}}$ \\ ${ }^{a}$ PhD Candidate, School of Management, Zhejiang University, 866 Yuhangtang Rd, \\ Hangzhou 310058, China P.R. \\ ${ }^{b}$ PhD Candidate, School of Public Affair, Zhejiang University, 866 \\ Yuhangtang Rd, Hangzhou 310058, China P.R.
}

\begin{abstract}
In this paper, we constructed a global trade computable general equilibrium model using the input-output table data in 2002, 2007, 2010, and 2015 to measure the border effect of the bilateral trade of agricultural products between China and the Belt and Road (B\&R) countries, and designed a simulation analysis under different scenarios for the impact of the B\&R initiative on China's agricultural trade. We discovered that: (1) The border effect of agricultural product trade between China and the B\&R countries decreased by $20.9 \%$ in 2015 compared with that in 2010, which means that the B\&R initiative to some extent reduced the trade barriers and promoted the bilateral agricultural trade between China and the B\&R countries. (2) There are different changes in border effect between China's domestic regions and between unilateral and bilateral border, the decline of border effect in China's costal area is larger than that in inland area, and the decline in import border is larger than that in export border. (3) With the improvement of the B\&R framework and the implementation of supporting policies, the decline in trade costs and in local agricultural product preference as well as the agricultural technology progress will further reduce the border effect. China's domestic regional trade gap will gradually narrow, the bilateral agricultural trade will be highly active, and the continuous growth of agricultural trade will emerge between China and the B\&R countries.
\end{abstract}

Keywords: Belt and Road, agricultural trade, border effect, CGE model JEL code: F14, Q13

(i)Corresponding author: jqdang@zju.edu.cn 


\section{Introduction}

The Belt and Road (B\&R) initiative proposed by the Chinese government has recently received worldwide attention. Throughout history, agricultural trade and foreign communication have always been the main focus of the Silk Road and Maritime Silk Road. Nowadays, the B\&R regions span more than 60 countries, covering $64 \%$ of the global population and $30 \%$ of the world's gross domestic product (GDP) (Huang, 2016). China has also been undergoing a rapid development of agricultural production and the increasing degree of opening-up. Moreover, the B\&R countries have become the new growth points of China's foreign trade against the background of global economic slowdown. Thus, making good use of agricultural resources and markets in the B\&R countries to enhance the level of the agricultural trade cooperation becomes significant to China (Fan et al., 2016; He et al., 2016; Song, 2014; Zhan, 2018). Therefore, the exploration of how the B\&R initiative impacts the trade of agricultural products for China - the world's largest developing country - is of great theoretical and practical significance.

Currently, the existing literature on the bilateral trade of agricultural products between China and the B\&R countries mainly focuses on the Heckscher-Ohlin theory, using a gravity model and network analysis to examine the competitiveness and complementarity of China's agricultural products in bilateral trade from the perspective of resource endowments, market structures, trade patterns, and technologies, and to analyze the various effects of competitiveness and complementarity on the future development of bilateral trade (Chen et al., 2014; Han et al., 2015; He et al., 2016; Rong and Yang, 2006; Sun and Li, 2013; Yao, 2006; Zhan, 2018). Other studies in the field are based on the new trade theory, using econometric approaches, such as fixed-effect regression, generalized method of moments, and difference-in-differences to explore the impact of the B\&R initiative on the agricultural trade between China and the B\&R countries, such as the structure and flow of import and export trades, binary marginal effects, and promotion of domestic agriculture (Huang et al., 2018; Lv, 2006; Sun and Li, 2016; Sun et al., 2017; Zhang and Tang, 2017).

Although the literature has deeply and comprehensively studied the issues related to the agricultural trade between China and the B\&R countries from various perspectives, a research gap still exists, characterized by insufficient analysis of trade barriers that were closely related to the bilateral trade. Most studies have only examined the impact of the tariff changes on China's agricultural trade while ignoring non-tariff, information, and other types of trade barriers that are difficult to measure (Lai and Li, 2007; Qiu et al., 2007; Zhou et al., 2006). Some studies on trade in other regions only examined the impact of a single type of non-tariff barrier on bilateral trade (Chen et al., 2018; Disdier and Marette, 2010; Disdier et al., 2008; Henson and Loader, 2001; Otsuki et al., 2001a,b; Wilson and Otsuki, 2004; Winchester et al., 2012). However, the border effect can fully depict the negative impact of the existence of a country's border on its bilateral trade with other countries, covering all the negative effects in bilateral trade. This effect was first discovered by McCallum (1995), who worked out that the average trade volume between two Canadian provinces is 22 times higher than that between one Canadian province and one American state by the gravity equation. However, for the two countries that are geographically adjacent and have similar language, culture, and system, this result is difficult to explain with traditional trade theories. Obstfeld and Rogoff (2000) called this discovery the 'border effect'. Subsequently, considerable literature has started discussing the border effect (Anderson and Van Wincoop, 2003, 2004; Baier and Bergstrand, 2001; Balistreri and Hillberry, 2007; Evans, 2003, 2006; Feenstra, 2002; Gong and Wang, 2014; Gong et al., 2012; Head and Ries, 2001; Helliwell and Verdier, 2001; Hillberry, 2002; Liu and Xin, 2011; Olper and Raimondi, 2008; Yi, 2003). The change of border effect can reflect the change of trade barrier and bilateral trade flow. Small border effects indicate that trade barriers have less negative impact on bilateral trade, which means that in the case where other conditions would remain unchanged, the trade barriers between the two countries would decline and the bilateral trade would increase. Therefore, studying the border effect is helpful in understanding the changes of trade barriers between China and the B\&R countries and the impact of the B\&R initiative on China's agricultural trade.

In this paper, we constructed a global trade computable general equilibrium (CGE) model to measure the border effect of the bilateral trade of agricultural products between China and the B\&R countries on the 
basis of the literature analysis and empirical facts and designed a simulation analysis under various scenarios for the impact of the B\&R initiative on China's agricultural trade. The core contributions of this paper are the following:

1. Determining the impact of policies on trade is difficult because the influencing factors of the bilateral trade of agricultural products are numerous and the influence mechanism is complex. The CGE model provided in this paper has selected the border effect as the research object to systematically investigate the magnitude and mechanism of the impact of the B\&R initiative on the agricultural trade of relevant countries or regions, which is a rigorous, comprehensive, and intuitive approach.

2. This study covers abundant input-output data from 30 Chinese provinces and $65 \mathrm{~B} \& \mathrm{R}$ countries or regions, analyzing the changes in the border effect in 2002, 2007, 2010, and 2015, and effectively making up for the limitations of the existing studies in which regional heterogeneity cannot be investigated and dynamic effects cannot be characterized due to incomplete data.

3. This study innovatively designs different scenario simulations based on the supporting polices for the B\&R initiative, including reduce in trade cost, sustained and stable economic growth of the B\&R countries, progress in agricultural production technology and decline in local agricultural products preference, which provide predict for future bilateral agricultural trade and thus depict the B\&R initiative induced policy effect and long-term economic impact. This is of great policy significance to the agricultural foreign trade firms and governments of China and the B\&R countries, providing an effective reference for firm's decisions and guiding the government to formulate relevant trade policies to a certain extent.

\section{Background}

\subsection{Belt and Road initiative}

Chinese President Xi Jinping called for the construction of a new regional cooperation model by jointly building the Silk Road Economic Belt during his visit to Kazakhstan on September 7, 2013. A month later, in Indonesia, President Xi Jinping again called for the establishment of the $21^{\text {st }}$ Century Maritime Silk Road. These development strategies and frameworks, all of which focus on connectivity and cooperation among countries primarily between China and the rest of Eurasia, are officially called the Silk Road Economic Belt and the $21^{\text {st }}$ century Maritime Silk Road, also known as the B\&R initiative' ${ }^{1}$. This initiative was written into the 'decision of the Central Committee of the Communist Party of China on some major issues concerning comprehensively deepening the reform, ${ }^{2}$ in November 201s3, which was adopted by the Central Committee of the Communist Party of China in the Third Plenum of the $18^{\text {th }}$ National Congress as a key policy priority before 2020. The National Development and Reform Commission, Ministry of Foreign Affairs, and Ministry of Commerce of the People's Republic of China issued the 'Vision and actions on jointly building silk road economic belt and $21^{\text {st }}$ century maritime silk road' ${ }^{3}$ with State Council authorization on March 28, 2015, indicating that the top-level design of the B\&R initiative tends to perfect. The holding of the Belt and Road Forum for International Cooperation and the releasing of 'joint communique of the leader's roundtable of the Belt and Road Forum for international cooperation'4 in March 2017 signified that the B\&R initiative ${ }^{5}$ has entered a new stage.

\footnotetext{
${ }^{1}$ Original information at the Belt and Road portal (https://eng.yidaiyilu.gov.cn/). This website aims to promptly respond to major domestic and international concerns, and scientifically and accurately explain the core concept of the B\&R initiative.

2 The document is available online at https://www.mfa.gov.cn/ce/cejm/chn/zggk/t1101725.htm.

3 The document is available online at: https://www.fmprc.gov.cn/ce/cevn/chn/sghkt/t1251121.htm, including eight parts: background, principles, framework, cooperation priorities, cooperation mechanisms, China's regions in pursuing opening-up, China in action, embracing a brighter future together.

${ }^{4}$ The document is available online at: http://www.beltandroadforum.org

${ }^{5}$ The principles of the B\&R initiative are the following: open for cooperation, harmonious and inclusive, market-oriented, and has mutual benefits. The four ideals of the B\&R initiative are peace and cooperation, openness and inclusiveness, mutual benefit, and mutual learning. The three communities of the B\&R initiative are a community of responsibility, a community of shared interests, and a community of destiny; four features of the Silk Road: green, healthy, intelligent, and peaceful; eight requirements of the B\&R initiative: effectively promote unity in thought, effectively promote the implementation of plants, effectively promote concerted coordination, effectively carry out key projects, effectively promote financial innovation, effectively promote people-to-people bond, effectively promote public opinion, and effectively promote safety and security. For additional details about the B\&R initiative, see: https://eng.yidaiyilu.gov.cn/ztindex.htm
} 
The B\&R initiative aims to promote the connection of Asian, European, and African continents and their adjacent seas; establish and strengthen partnerships among the B\&R countries; create all-dimensional, multi-tiered, and composite cooperation; and realize diversified, independent, balanced and sustainable developments in these countries.

Unimpeded trade is one of the five major goals of the cooperation priorities of the B\&R initiative. In the $\mathrm{B} \& \mathrm{R}$ official documents ${ }^{6}$, the importance of trade is reiterated, and agricultural trade is regarded as a deep cooperation area of the trade between China and the B\&R countries, and the Chinese government makes a commitment to take measures that effectively decline the border effect, including, but not limited to, the following aspects: to open free trade areas; to enhance information exchange and mutual recognition of regulations; to promote cooperation in the fields of certification and accreditation, standard measurement, and statistical information; to reduce non-tariff barriers; to jointly improve the technical trade measures' transparency; and to enhance trade liberalization and facilitation.

The following five main programs sponsored by the B\&R initiative are conducive to the development of trade between China and the B\&R countries: (1) China Railway Express, which was an important carrier for deepening economic and trade cooperation between China and the B\&R countries; (2) free trade zones with the B\&R countries, where the import and export tariff on foreign goods is zero; (3) Silk Road Fund, which was committed to provide investment and financial support for economic and trade cooperation and bilateral and multilateral connectivity within the B\&R framework; (4) Asian Infrastructure Investment Bank, which aims to promote the interconnectivity of the construction and process of economic integration in Asia; and (5) Regional Comprehensive Economic Partnership, which aims to establish a free trade agreement for a uniform market by reducing the tariff and non-tariff barriers.

\subsection{Agricultural trade between China and the Belt and Road countries}

The B\&R countries have a long history of agricultural civilization and rich resources of agriculture, forestry, animal husbandry, fishery, and market. These countries occupy an important position in world agriculture and are the key targets of China's agricultural trade and foreign agricultural cooperation. The total agricultural import and export trade volume of the B\&R countries was approximately 751 billion US dollars in 2015, accounting for nearly quarter of the world's total agricultural trade. The total agricultural import and export trade volume between China and the B\&R countries was approximately 45 billion US dollars in the same year, accounting for approximately $6 \%$ the B\&R countries' total agricultural trade; thus, China has become the largest trading partner of the B\&R countries, replacing the US and Germany. Meanwhile, the B\&R countries are the main trading partners of China. The proportion of the total agricultural import and export trade volume between China and the B\&R countries in China's total agricultural trade increased from approximately $18 \%$ in 2005 to approximately $24 \%$ in 2015 . The agricultural trade between China and the B\&R countries from 2005 to 2015 showed a tendency to increase. This trade also obtained a $374 \%$ total increase and a 16\% average increase. China has been generally in a deficit position in agricultural trade between China and the B\&R countries. However, an improvement in this trade deficit has been shown since the implementation of the B\&R initiative.

ASEAN countries share more than $70 \%$ of the total agricultural import and export trade volume between China and the B\&R countries, given the geographical proximity and the commencement of the China-ASEAN Free Trade Area. The rest of the total trade volume is divided among Mongolia and Russia, Central and East Europe, South Asia, West Asia, and Central Asia. From a national perspective, Thailand, Indonesia, Vietnam, and Malaysia have the majority of the agricultural import and export trade volume between China and the B\&R countries (over 50\%). In terms of the commodity structure of agricultural products trade between China and the B\&R countries, the main export commodities of China are fruits and vegetables, aquatic products, and processed foods; the main import commodities of China are fruits and vegetables, edible oil and grease, textile fiber, and rubber.

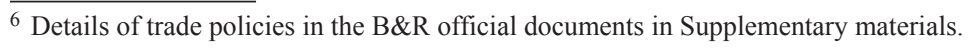




\section{Empirical model}

\subsection{Global trade computable general equilibrium model}

In this study, we construct a global trade CGE model in which we divide the world into three parts: mainland China, the B\&R countries, and other parts of the world ${ }^{7}$. The China regional division standard provided by the State Information Center (SIC) divides mainland China into eight regions ${ }^{8}$, we streamline the standard and divide mainland China into five regions: Northeastern China, Northern China, Southeastern Coastal Area in China, Central China, and Western China. The specific provinces included in each region are presented in Table 1. The 65 B\&R countries are grouped into East Asia, West Asia, South Asia, Central Asia, Commonwealth of Independent States, and Central and Eastern Europe, according to the 'Blue book of industrialization: the Belt and Road national industrialization process report' issued by the Chinese Academy of Social Science. The countries included in each region are specified in Table 2.

\footnotetext{
7 The global trade CGE model has to consider the general equilibrium of all markets in the world. However, since the research object are China and the B\&R countries, the other countries (regions) in the world are merged into one subject and are not taken as analysis object; meanwhile, to study the heterogeneity of changes in border effect between China's domestic regions, China mainland is further divided into five regions.

${ }^{8}$ The inter-regional input-output table of China provided by SIC divides mainland China into the Northeastern China, Beijing and Tianjin Area, Northern Coastal Area, Eastern Coastal Area, Southern Coastal Area, Central China, Northwestern China, and Southwestern China. In this study, we retain Northeastern China and Central China, and we combine the Beijing and Tianjin Area and Northern Coastal Area into Northeastern China, combine the Eastern Coastal Area and Southern Coastal Area into Southeastern Coastal Area, and combine Northwestern China and Southwestern China into Western China.
}

Table 1. Division of China mainland in global trade computable general equilibrium model. ${ }^{1}$

\begin{tabular}{ll}
\hline Regions & Provinces \\
\hline Northeastern China & Heilongjiang, Jilin, Liaoning \\
Northern China & Beijing, Tianjin, Hebei, Shandong \\
Southeastern China & Shanghai, Jiangsu, Zhejiang, Guangdong, Fujian, Hainan \\
Central China & Shanxi, Henan, Anhui, Jiangxi, Hubei, Hunan \\
Western China & Inner Mongolia, Shaanxi, Gansu, Ningxia, Qinghai, Xinjiang, Yunnan, Guizhou, \\
& Sichuan, Chongqing, Guangxi, Tibet \\
\hline${ }^{1}$ Based on the 'Inter-regional input-output table of China' (State Information Center, 2005).
\end{tabular}

Table 2. Division of the Belt and Road countries. ${ }^{1}$

\begin{tabular}{ll}
\hline Regions & Countries \\
\hline East Asia & Mongolia, Singapore, Malaysia, Indonesia, Myanmar, Thailand, Laos, \\
& Cambodia, Vietnam, Brunei, Philippines \\
West Asia & $\begin{array}{l}\text { Iran, Iraq, Turkey, Syria, Jordan, Lebanon, Israel, Palestine, Saudi Arabia, } \\
\text { Yemen, Oman, United Arab Emirates, Qatar, Kuwait, Bahrain, Greece, } \\
\text { Cyprus, Sinai Peninsula }\end{array}$ \\
South Asia & India, Pakistan, Bangladesh, Afghanistan, Sri Lanka, Maldives, Nepal, \\
& Bhutan \\
Central Asia & Kazakhstan, Uzbekistan, Turkmenistan, Tajikistan, Kyrgyzstan \\
Commonwealth of Independent States & Russia, Ukraine, Belarus, Georgia, Azerbaijan, Armenia, Moldova \\
Central and Eastern Europe & $\begin{array}{l}\text { Poland, Lithuania, Estonia, Latvia, Czech Republic, Slovakia, Hungary, } \\
\text { Slovenia, Croatia, Bosnia and Herzegovina, Montenegro, Serbia, Albania, } \\
\text { Romania, Bulgaria, Macedonia }\end{array}$ \\
\hline
\end{tabular}

${ }^{1}$ Based on the 'Blue book of industrialization: the Belt and Road national industrialization process report' (Chinese Academy of Social Science, 2016). 
The CGE model in this study consists of production, demand, trade, and equilibrium modules, which includes 487 formula in 32 equations. Only the main frame structure and core assumptions of the model are introduced due to the space constraint. The main formula involved in the bilateral trade activities is presented in Table 3. In this study, we assume that the like products produced in China and in other parts of the world cannot be completely substituted (Armington, 1969), and the relationship among these products is described by the Constant Elasticity of Substitution (CES) production function. Hence, the international trade between

Table 3. Main equations in global trade computable general equilibrium model.

\begin{tabular}{|c|c|}
\hline Meaning & Equations \\
\hline \multicolumn{2}{|l|}{ Production module } \\
\hline First-stage production function & $Q_{i t}=A_{i t}\left[\alpha_{i t b} B_{i t}{ }^{\left(\sigma_{i t}-1\right) / \sigma_{i t}}+\alpha_{i t c} C_{i t}{ }^{\left(\sigma_{i t}-1\right) / \sigma_{i t}}\right]^{\sigma_{i t} /\left(\sigma_{i t}-1\right)}$ \\
\hline Second-stage added value production function & $B_{i t}=\left[\alpha_{i t k} K_{i t}\left(\sigma_{i t b}-1\right) / \sigma_{i t b}+\alpha_{i t l} L_{i t}\left(\sigma_{i t b}-1\right) / \sigma_{i t b}\right]^{\sigma_{i t b} /\left(\sigma_{i t b}-1\right)}$ \\
\hline $\begin{array}{l}\text { Second-stage intermediate input production } \\
\text { function }\end{array}$ & $C_{i t}=\left[\sum_{t^{\prime}} \alpha_{i t t^{\prime}} M_{i t t^{\prime}}{ }^{\left(\sigma_{i t c}-1\right) / \sigma_{i t c}}\right]^{\sigma_{i t c} /\left(\sigma_{i t c}-1\right)}$ \\
\hline $\begin{array}{l}\text { Third-stage intermediate input production } \\
\text { function }\end{array}$ & $M_{i t t^{\prime}}=\left[\sum_{i^{\prime}} \alpha_{i t t^{\prime} i^{\prime}} M_{i t t^{\prime} i^{\prime}}{ }^{\left(\sigma_{i t t^{\prime}}-1\right) / \sigma_{i t t^{\prime}}}\right]^{\sigma_{i t t^{\prime}} /\left(\sigma_{i t t^{\prime}}-1\right)}$ \\
\hline
\end{tabular}

No.

Demand module

First-stage utility function $\quad U_{i}=\left[\sum_{t} \alpha_{i t} q_{i t}{ }^{\left(\sigma_{i}-1\right) / \sigma_{i}}\right]^{\sigma_{i} /\left(\sigma_{i}-1\right)}$

Budget constraints faced by the first-stage utility $\sum_{t} p_{i t} q_{i t}=K_{i} r_{k}+L_{i} w_{l}$
function

Second-stage utility function

$U_{i t}=\left[\sum_{i^{\prime}} \alpha_{i t i^{\prime}} q_{i t i^{\prime}}{ }^{\left(\sigma_{i t m}-1\right) / \sigma_{i t m}}\right]^{\sigma_{i t m} /\left(\sigma_{i t m}-1\right)}$

Budget constraints faced by the second-stage $\quad p_{i t} q_{i t}=\sum_{i^{\prime}} p_{i t i^{\prime}} q_{i t i^{\prime}}$
utility function

Trade module

Bilateral trade flow $\quad x_{i i^{\prime} t}=q_{i t i^{\prime}}+\sum_{i^{\prime}} M_{i t^{\prime} t i^{\prime}}$

Equilibrium module

Product market equilibrium conditions

$Q_{i t}=\sum_{i^{\prime}} q_{i^{\prime} t i}+\sum_{i^{\prime}, t^{\prime}} M_{i^{\prime} t^{\prime} t i}$

Factor market equilibrium conditions

$K_{i}=\sum_{t} K_{i t}, L_{i}=\sum_{t} L_{i t}$ 
China and other parts of the world is embodied in the intermediate input demand and the final demand for product production.

\section{- Production module}

In this study, we assume that production activities are divided into agricultural, manufacturing, and service sectors, with each sector producing only one product. Thus, the three-layer nested CES production function can be used to describe the production activities in each region (Equations 1-4 in Table 3). Equation 1 depicts the first stage CES production function of the representative manufacturers, where $Q_{i t}$ represents the quantity of product $t$ produced by region $i . B_{i t}$ and $C_{i t}$ represent the added value and intermediate input of product $t$, respectively; $\alpha_{i t b}$ and $\alpha_{i t c}$ are the corresponding share parameters of the added value and intermediate input in the CES function, respectively. $A_{i t}$ is the output measurement parameter of product $t$ (i.e. production technical parameter); $\sigma_{i t}$ is the index of substitution elasticity of added value and intermediate inputs. The production function of added value and intermediate input in the second stage is shown in Equations 2 and 3 , respectively. $K_{i t}$ and $L_{i t}$ represent the capital and labor inputs in the production process of product $t$ in region i. $\alpha_{i t k}$ and $\alpha_{i t l}$ are the share parameters of the capital and labor inputs in the CES function, respectively. $\sigma_{i t b}$ is the index of the substitution elasticity of the capital and labor inputs. $M_{i t t}$ is the amount of $t$ ' (the product itself) used in the production of product $t$ in region $i^{9}$, and $\alpha_{i t t}$ is the corresponding share parameter; $\sigma_{i t c}$ is the index of substitution elasticity of various intermediate inputs used in the process of producing product $t$ in region $i$. Equation 4 represents the CES production function of intermediate input in the third stage, where $M_{i t t^{\prime}}{ }^{\prime}$, represents the usage amount of product $t$ ' produced by region $i$ ' in the process of producing product $t$ in region $i$, and $\alpha_{i t t^{\prime} i}$, is the corresponding share parameter; $\sigma_{i t t}$, is the index of the elasticity substitution of products in various areas.

The perfect competitive market structure is assumed to exist in three production stage; thus, representative manufacturers seek to maximize profits. Therefore, we can construct Lagrange function to calculate the added value and intermediate input function, the labor and capital input function, the demand function for various products in production progress, and the demand function for like products from various regions in production progress. Moreover, the production function of one stage can be used to construct the corresponding unit cost function in the previous stage.

\section{- Demand module}

This study adopts two-layer nested CES utility function to describe the final demand of products in various regions (Equations 5-8 in Table 3). The utility function in the first stage can be expressed as Equation 5, where $U_{i}$ represents the utility of representative consumers in region $i$ in the first stage, $q_{i t}$ represents the final demand for synthetic product ${ }^{2} t$ in region $i, \alpha_{i t}$ is the corresponding share parameter, and $\sigma_{i}$ is the index of substitution elasticity of different synthetic products consumed in region $i$. The progress of the consumption of synthetic product $t$ in region $i$ faced the constraint in the Equation $6^{10}$, where $K_{i}$ and $L_{i}$ represent the capital and labor endowments of region $i$, respectively, while $r_{k}$ and $w_{l}$ represent the capital price and labor price of region $i$, respectively. $P_{i t}$ represents the price of synthetic product $t$ consumed by region $i$, and $q_{i t}$ represents the consumption of synthetic product $t$. Equation 7 depicts the CES utility function in the second stage, where $U_{i t}$ represents the utility of representative consumers in region $i$ in the second stage, $q_{i t i}$, represents the demand in region $i$ for the synthetic product produced by region $i$, $\alpha_{i t i}$, is the corresponding share parameter, and $\sigma_{i t m}$ is the index of substitution elasticity of different synthetic product $t$ produced in different regions. Equation 8 shows the budget constraints faced by region $i$, where $p_{i t i},=p_{t i}, c_{i i}$, represents the consumer price in region $i$ of product $t$ produced by region $i^{\prime}, p_{t i}$, is the production price of product $t$ in region $i^{\prime}$, and $c_{i i}$, is the trade cost from region $i$ ' to region $i^{11}$

\footnotetext{
${ }_{9}^{9}$ Here, $t$ and $t$ ' refer to the same variable, which is the language habit of a model setting in GAMS.

${ }^{10}$ Synthetic product refers to the summation of the same products in different regions.

${ }^{11}$ In this study, the trade cost is the sum of transportation cost and tariff, where the transportation cost is $20 \%$ of the total bilateral agricultural trade and is borne by the importing country.
} 
Correspondingly, consumers are assumed to pursue utility maximization under budget constraints. Therefore, the final demand of region $i$ for synthetic product $t$ produced in various regions can be obtained by constructing the Lagrange function and applying first-order conditions. The utility function of the second stage can be used to calculate the unit cost function of the first stage.

The data of transportation cost and tariff and non-tariff factors are not included in our model, because the CES function is used to describe the substitution relationship of product produced in domestic and abroad, thus, the share parameters of the CES function can reflect the influence of transportation cost and tariff and non-tariff factors (Gong et al., 2012; Jia et al., 2017).

\section{- Trade module}

International trade is used to fulfill the final consumption and intermediate input demands in the process of producing various products. The bilateral trade flow can be expressed as Equation 9. $X_{i i t}$ represents the import in region $i$ of product $t$ produced in region $i^{\prime}, q_{i t i}$, represents the imported product used to meet final demand, while $\sum_{i}, M_{i t} t^{\prime}$, represents the imported product used as intermediate input.

\section{- Equilibrium module}

The market equilibrium in this study includes product and factor market equilibrium. Product market equilibrium must meet the conditions provided by Equation 10, where $Q_{i t}$ represents the quantity of product $t$ produced in region $i, \sum_{i}, q_{i t i}$ represents the final consumption in various regions, and $\sum_{i,{ }^{\prime}, t} M_{i{ }^{\prime}{ }^{t} t}$, represents the intermediate inputs in the production of different products in various regions. Factor market equilibrium includes labor supply and demand equilibrium as well as capital supply and demand equilibrium, while the equilibrium condition is presented in Equation 11, where $K_{i}$ and $L_{i}$ represent the capital and labor endowments in region $i$, respectively, while $K_{i t}$ and $L_{i t}$ represent the capital and labor input on the production progress of product $t$ in region $i$, respectively.

\subsection{Border effect}

The border effect measurement method is inferred on the basis of the improved gravity model provided by Anderson and van Wincoop (2003): the gravity model containing multilateral resistance is employed to show the trade situation. The comparative static analysis framework is then set up on the basis of conditions whether trade barrier exists. Finally, the border effect of bilateral trade is obtained through comparative static analysis. Equations 12-15 in Table 4 demonstrate the process.

Equation 12 is a gravity model that includes multilateral resistance, where $x_{i j}$ represents export from regions $i$ to $j, y_{i}$ and $y_{j}$ are the GDP of regions $i$ and $j$, respectively, $y^{w}$ is the total GDP of all regions, $t_{i j}$ represents the trade cost between regions $i$ and $j$, and $\sigma$ is the substitution elasticity index between all commodities. $P_{i}$ and $P_{j}$ are the so-called multilateral resistance. The bilateral trade volumes are not only affected by the trade barriers between countries $h$ and $k$, but also by the trade barriers between countries $h, k$ and their trade partners, however, the traditional gravity model fails to include the multilateral resistance, as the result, the model estimation and the calculation of border effect are deviate. We conduct a comparative static analysis according to Equation 14 in order to avoid the deficiency of traditional gravity model, where $h$ and $k$ represent different countries; $B B$ and $N B$ represent the average trade volume of $h$ and $k$ with and without borders, respectively; $P_{h}$ and $P_{k}$ represent multilateral resistance variable with borders; $p_{h}$ and $p_{k}$ represent multilateral resistance variable without borders; $b_{h k}{ }^{1-\sigma}$ represents the effect of bilateral resistance on average trade volume, and $\left(\frac{P_{h}^{\sigma-1}}{\tilde{p}_{h}^{\sigma-1}}\right)\left(\frac{P_{k}^{\sigma-1}}{\tilde{p}_{k}^{\sigma-1}}\right)$ represents the effect of multilateral resistance on average trade volume. 
Table 4. Border effect measurement equations.

\begin{tabular}{ll}
\hline Meaning & Equations \\
\hline Gravity model with multilateral resistance & $x_{i j}=\frac{y_{i} y_{j}}{y^{w}} \cdot\left(\frac{t_{i j}}{P_{i} P_{j}}\right)^{1-\sigma}$ \\
The determinative equation of multilateral resistance & $P_{j}^{1-\sigma}=\sum_{i} P_{i}^{1-\sigma} \vartheta_{i} t_{i j}^{1-\sigma}$ \\
Comparative static analysis of bilateral trade & $\frac{B B_{h k}}{N B_{h k}}=b_{h k}{ }^{1-\sigma}\left(\frac{P_{h}^{\sigma-1}}{\tilde{p}_{h}^{\sigma-1}}\right)\left(\frac{P_{k}^{\sigma-1}}{\tilde{p}_{k}^{\sigma-1}}\right)$ \\
Border effect measurement & $B H_{h k}=\frac{B B_{h h} / N B_{h h}}{B B_{h k} / N B_{h k}}$ \\
\hline
\end{tabular}

The border effect can be expressed as Equation 15 on the basis of Equation 14, where $B H_{h k}$ represents the border effect between country $h$ and $k$, while $h h$ and $h k$ represent domestic and international trade, respectively. $B B_{h h}$ and $B B_{h k}$ can be obtained from the base period data, while $N B_{h h}$ and $N B_{h k}$ can be obtained from the counterfactual simulation in the CGE model.

\section{Data description and model parameters}

We construct a dataset using the input-output data of China, the B\&R countries, and other parts of the world in 2002, 2007, 2010, and 2015. The dataset is constructed on the basis of four different sources.

1. The Development Research Center of the State Council of the People's Republic of China (DRC) provides the China input-output table. DRC contains the 'China SAM matrix in 2002', the 'interregional input-output tables for six sectors of 30 provinces' in 2007 and 2010, and the 'inter-regional input-output tables for eight sectors' in $2015 .{ }^{12}$

2. We compile the input-output table of the B\&R countries and other parts of the world. The trade data of agricultural, industrial, and service products are from the United Nations Commodity Trade Statistics Database of the United Nations Conference on Trade and Development (UNCTAD) $)^{13}$. World Bank (WB) provides the GDP data of the B\&R countries and other regions of the world. ${ }^{14}$ The national tariff data are obtained from World Integrated Trade Solution (WITS). ${ }^{15}$

3. Several industry sectors provided in the input-output table are reintegrated into three sectors agricultural, industrial, and service sectors - to ensure concise calculation without affecting the analysis of this paper. Thereafter, we aggregate the three input-output tables to obtain the global input-output table in 2002, 2007, 2010, and 2015 where contains agriculture, industry, and service sectors of five regions of China, the $\mathrm{B} \& \mathrm{R}$ countries, and other parts of the world. The social accounting matrix is generated using the cross-entropy method. In addition, we must use the actual data to simulate global trade data without border effect based on the above-mentioned input-output table, to obtain $N B_{h h}$ and $N B_{h k}$ with a counterfactual analysis. ${ }^{16}$

We estimate the factor and product substitution elasticities in the CGE model on the basis of historical data and existing literature. Table 5 shows the specific values. The output measurement and share parameters in

\footnotetext{
12 DRC available at: http://www.drcnet.com.cn

13 UNCTAD available at: https://unctadstat.unctad.org

14 WB available at: https://data.worldbank.org/indicator

15 WITS available at: https://wits.worldbank.org

16 We suppose that when no trade cost or bilateral trade barrier exists, one region consumes commodity from all other regions in proportion to their share of world income.
} 
Table 5. Value of substitution elasticity index in global trade computable general equilibrium model.

\begin{tabular}{|c|c|c|c|}
\hline $\begin{array}{l}\text { Elasticity } \\
\text { index }\end{array}$ & Substitute relationship & Value & References \\
\hline$\sigma_{i t}$ & Added value and intermediate inputs & 0.5 & Anderson and Van Wincoop (2004); Xin and \\
\hline$\sigma_{i t b}$ & Capital and labor inputs & 1.5 & $\begin{array}{l}\text { Wang (2008); Liu et al. (2010); Gong et al. } \\
\text { (2012) }\end{array}$ \\
\hline$\sigma_{i t c}$ & $\begin{array}{l}\text { Different intermediate inputs in the same } \\
\text { region }\end{array}$ & 2 & Anderson and Van Wincoop (2004); Yi (2003) \\
\hline$\sigma_{i}$ & Different synthetic products in the same region & 1.5 & Whalley and Xin (2009) \\
\hline$\sigma_{i t t}$ & Same product from different regions & 2.5 & Yi (2003); Zhang (2009); Jia et al. (2017) \\
\hline$\sigma_{i t m}$ & Same synthetic product from different regions & 2 & Whalley and Xin (2009) \\
\hline
\end{tabular}

the model are obtained according to the social accounting matrix through the calibration method. In Table 6 , we only report the output measurement parameter of agricultural sector $A_{i t}$ and the share parameter $\sigma_{i t i}$ calibrated using real data and simulation data in 2015, respectively, due to limited space. The share parameter reflects the final demand of agricultural products in each region. Furthermore, 500 random value tests are performed in the \pm 1 interval of each parameter of the model to ensure the robustness of the final result. In this

Table 6. Calibration values of parameters in global trade computable general equilibrium model.

\begin{tabular}{|c|c|c|c|c|c|c|}
\hline & & \multirow{2}{*}{$\begin{array}{l}A_{i t} \\
\text { (agriculture) }\end{array}$} & \multicolumn{2}{|c|}{$\sigma_{i t i},($ raw data $)$} & \multicolumn{2}{|c|}{$\sigma_{i t i},($ simulated data $)$} \\
\hline & & & China & B\&R & China & $\mathbf{B \& R}$ \\
\hline \multirow{7}{*}{2002} & Northeastern China & 4.0243 & 0.7169 & 0.0344 & 0.3915 & 0.1896 \\
\hline & Northern China & 11.226 & 0.7654 & 0.0958 & 0.3915 & 0.1896 \\
\hline & Southeastern China & 6.9935 & 0.6623 & 0.0572 & 0.3915 & 0.1896 \\
\hline & Central China & 5.4390 & 0.7229 & 0.0159 & 0.3915 & 0.1896 \\
\hline & Western China & 9.0814 & 0.8503 & 0.0675 & 0.3915 & 0.1896 \\
\hline & The B\&R countries & 6.4567 & 0.1168 & 0.6666 & 0.3915 & 0.1896 \\
\hline & Other parts of the world & 5.2503 & 0.0925 & 0.7413 & 0.3915 & 0.1896 \\
\hline \multirow[t]{7}{*}{2007} & Northeastern China & 4.8800 & 0.7401 & 0.0558 & 0.4306 & 0.1684 \\
\hline & Northern China & 10.926 & 0.8187 & 0.0841 & 0.4306 & 0.1684 \\
\hline & Southeastern China & 5.8644 & 0.7143 & 0.0586 & 0.4306 & 0.1684 \\
\hline & Central China & 5.6599 & 0.7874 & 0.0173 & 0.4306 & 0.1684 \\
\hline & Western China & 9.3526 & 0.8325 & 0.0659 & 0.4306 & 0.1684 \\
\hline & The B\&R countries & 6.0109 & 0.1159 & 0.5864 & 0.4306 & 0.1684 \\
\hline & Other parts of the world & 5.5987 & 0.1023 & 0.7704 & 0.4306 & 0.1684 \\
\hline \multirow[t]{7}{*}{2010} & Northeastern China & 4.9886 & 0.7695 & 0.0493 & 0.4792 & 0.1125 \\
\hline & Northern China & 11.546 & 0.8336 & 0.0985 & 0.4792 & 0.1125 \\
\hline & Southeastern China & 7.8211 & 0.7946 & 0.0654 & 0.4792 & 0.1125 \\
\hline & Central China & 6.1347 & 0.8428 & 0.0220 & 0.4792 & 0.1125 \\
\hline & Western China & 8.9762 & 0.8958 & 0.0593 & 0.4792 & 0.1125 \\
\hline & The B\&R countries & 7.0209 & 0.0993 & 0.5677 & 0.4792 & 0.1125 \\
\hline & Other parts of the world & 5.2496 & 0.1205 & 0.6913 & 0.4792 & 0.1125 \\
\hline \multirow[t]{7}{*}{2015} & Northeastern China & 4.3995 & 0.9124 & 0.0556 & 0.4521 & 0.1876 \\
\hline & Northern China & 12.143 & 0.8901 & 0.0842 & 0.4521 & 0.1876 \\
\hline & Southeastern China & 7.0556 & 0.9483 & 0.0477 & 0.4521 & 0.1876 \\
\hline & Central China & 4.4782 & 0.9657 & 0.0119 & 0.4521 & 0.1876 \\
\hline & Western China & 9.6547 & 0.9449 & 0.0513 & 0.4521 & 0.1876 \\
\hline & The B\&R countries & 5.3453 & 0.2492 & 0.5463 & 0.4521 & 0.1876 \\
\hline & Other parts the world & 6.0138 & 0.1581 & 0.7157 & 0.4521 & 0.1876 \\
\hline
\end{tabular}


study, the CGE model is constructed by GAMS (General Algebraic Modeling System, Fairfax, VA, USA), and the mixed complementary problem strategy is used to solve the hybrid solution problem of linear and nonlinear equations in the model. Finally, all equilibrium solutions are obtained by the PATH solver in GAMS.

\section{Empirical analysis}

This chapter consists of two parts. In the first part, we measure the border effect of the bilateral agricultural trade between China and the B\&R countries with a global trade CGE model using the input-output table data in 2002, 2007, 2010, and 2015. Thus, we preliminarily examine the impact of the B\&R initiative on China's agricultural trade from 2010 to 2015. In the second part, we design a simulation analysis contains four different scenarios based on the improvement of the B\&R initiative, the development of the world economy, the agricultural technology progress, and inter-regional changes in demand for agricultural products to analyze the long-term impact of the B\&R initiative on China's agricultural trade.

\subsection{Border effect measurement}

The equilibrium trade flows $N B_{h h}$ and $N B_{h k}$ under ideal conditions are measured by replacing the agricultural sector parameters calibrated from the real dataset with the corresponding parameters calibrated from the simulated dataset. Subsequently, we use Equation 15 to measure the border effect of bilateral agricultural trade. Table 7 presents the detailed results.

We further provide the average annual change rate of border effect of the agricultural trade between China and the B\&R countries (Figure 1) based on Table 7. It can be seen from Table 7 and Figure 1, the border effect of bilateral agricultural trade between China and the B\&R countries has gradually declined over the past 15 years with extensive linkages and close cooperation of the regional economy. The decline from 2010 to 2015 is the largest, suggesting that the B\&R initiative has promoted the bilateral agricultural trade between China and the $\mathrm{B} \& \mathrm{R}$ countries to an extent. In terms of China's domestic regions, the unilateral and bilateral effects of agricultural trade between Northern and Southern China and the B\&R countries have exhibited a steady downward trend, and the decline between 2010 and 2015 is relatively large. The unilateral and bilateral border effects of agricultural trade between Western China and the B\&R countries have increased to some extent, however, the uptrend has slowed down after 2010. The bilateral effects and import unilateral effects of agricultural trade between Northeastern China and the B\&R countries have continued to decline, especially between 2010 and 2015, but the export unilateral effect of that showed a slight increase. The bilateral effects and export unilateral effects of agricultural trade between Central China and the B\&R countries have also continued to decline, and the decline between 2010 and 2015 is significant, but the import unilateral effects of that have exhibited a slight increase.

Specifically, the bilateral effect of agricultural trade between China and the B\&R countries has continued to decline from 16.8 in 2002, especially, the bilateral effect has decreased from 14.3 in 2010 before the implementation of the B\&R initiative to 11.3 in 2015 after the implementation of the B\&R initiative, indicating that from 2010 to 2015 , the inter-regional agricultural trade barriers have decreased by $20.9 \%$. This decrease suggests that the implementation and improvement of the B\&R initiative play an important role in promoting the decline of agricultural trade barriers and the increase of bilateral trade between China and the B\&R countries. In addition, the decline in import border is larger than that in export border which means that the growth of China agricultural import trade with the B\&R countries is higher than that of the export trade over the past five years, indicating that China's regional import dependence on agricultural products has a growing trend with the implementation and improvement of the $\mathrm{B} \& \mathrm{R}$ initiative $\mathrm{e}^{17}$.

In terms of regional differences within China, the border effect of bilateral agricultural trade between all regions in China except Western China and the B\&R countries has declined over the past 15 years, and the

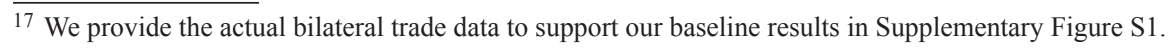


Table 7. Border effects of agricultural trade between China and the Belt and Road countries. ${ }^{1}$

\begin{tabular}{lllll}
\hline & & Bilateral effect & Unilateral effect & \\
\cline { 3 - 4 } & & Export border & Import border \\
\hline 2002 & China & 16.774 & 19.647 & 12.177 \\
& Northeastern China & 20.067 & 28.660 & 13.864 \\
& Northern China & 12.953 & 12.295 & 21.763 \\
& Southeastern China & 7.2336 & 0.8538 & 7.9565 \\
Central China & 98.375 & 67.359 & 179.24 \\
& Western China & 234.68 & 69.441 & 501.21 \\
China & 15.658 & 19.126 & 11.303 \\
& Northeastern China & 19.669 & 28.545 & 11.876 \\
& Northern China & 11.543 & 11.160 & 20.452 \\
& Southeastern China & 6.7160 & 0.6944 & 5.3479 \\
& Central China & 99.148 & 65.439 & 180.88 \\
Western China & 239.71 & 70.502 & 584.72 \\
China & 14.245 & 18.676 & 9.9465 \\
& Northeastern China & 18.701 & 28.672 & 10.623 \\
Northern China & 10.763 & 10.187 & 20.427 \\
Southeastern China & 5.9554 & 0.4463 & 4.1185 \\
Central China & 96.739 & 60.528 & 183.95 \\
Western China & 253.49 & 75.434 & 599.01 \\
China & 11.264 & 15.147 & 5.2163 \\
Northeastern China & 16.990 & 29.933 & 6.3447 \\
Northern China & 7.7782 & 8.0164 & 18.019 \\
Southeastern China & 3.2147 & 0.3238 & 0.9483 \\
Central China & 87.645 & 52.996 & 198.37 \\
Western China & 257.84 & 88.372 & 521.74 \\
\hline
\end{tabular}

${ }^{1}$ Bilateral effect represents the border effect of total import and export trade of agricultural products between China and the B\&R countries; Unilateral effect respectively represents the border effect of import and export trade of agricultural products between China and the B\&R countries; Export border represents the border effect of China's export trade to the B\&R countries; Import border represents the border effect of China's import trade from the B\&R countries.

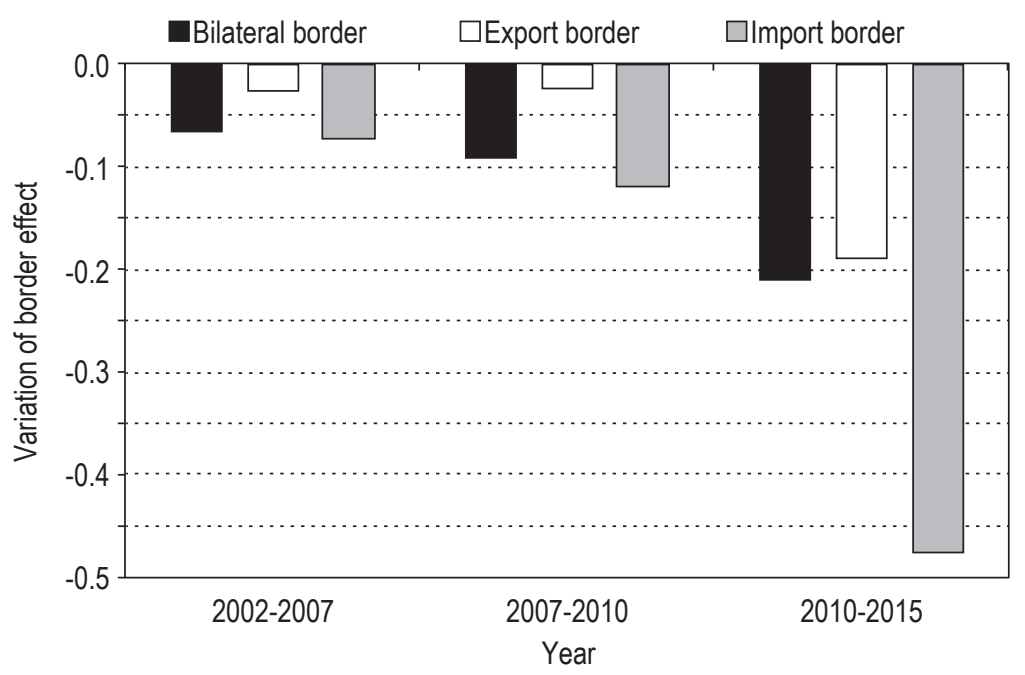

Figure 1. The average annual change rate of the border effect between China and the Belt and Road countries. 
decline from 2010 to 2015 is particularly evident. Moreover, the border effect of agricultural trade between the Southeastern Coastal Areas and the B\&R countries decreased from 7.2 in 2010 to 3.2 in 2015, suggesting that bilateral trade barriers of Southeastern Coastal China have decreased by more than $46 \%$, the decrease is larger than those of other regions in China, indicating that the B\&R initiative has promoted agricultural trade between the coastal areas in China and the B\&R countries more than between the inland areas in China and the B\&R countries, although the border effect of coastal areas is always the smallest. The border effect between Western China and the B\&R countries has continued to rise during the sample period. However, the uptrend during 2010 to 2015 has significantly slowed, indicating that the B\&R initiative has curbed the agricultural trade barriers in Western China to an extent.

With regard to the unilateral effect, the import and export border of agricultural trade between China and the B\&R countries has fallen by approximately 47.6 and $18.9 \%$ from 2010 to 2015 , which means that the implementation of the B\&R initiative is more conductive to China's agricultural products imports on the basis of reducing trade barriers and promoting the overall growth of bilateral trade. This indicates that China further meets the demand for agricultural products through imports as well as the B\&R countries have been fully utilized the comparative advantages of agricultural products, reflecting the further improvement and optimization of regional agricultural product market division and resource allocation. The changes in unilateral effect of China's domestic regions are basically consistent with that of entire China, and the B\&R initiative has the most obvious promotion effect on agricultural import and export of Southeast coastal area, of which the import and export border has decreased by about 76.9 and $27.4 \%$, showing that on the one hand, the coastal areas have more sensitivity toward the B\&R initiative than the inland areas, on the other hand, the changes in industrial structure of coastal areas with relatively high economic development level result in the increase of demand for agricultural import; the increase in export border of Northeastern and Western China and in the import border of Central China may be that the relatively backward economic development level and infrastructure construction of these regions have diluted the policy effect of the B\&R initiative.

\subsection{Scenario simulation analysis}

The above four-period border effect reflects the agricultural trade barriers and their changes between China and the B\&R countries before and after the launch of the B\&R initiative. Furthermore, we take the 'Vision and actions on jointly building silk road economic belt and $21^{\text {st }}$ century maritime silk road' issued by the National Development and Reform Commission, Ministry of Foreign Affairs, and Ministry of Commerce of the People's Republic of China in 2015 as the background, and design four different scenario simulations (Table 8$)^{18}$ according to specific situations that may appear in the future. The specific situations include the decline of trade costs associated with increasing regional economic ties, the sustained and steady economic growth of B\&R trading partners in a certain period, the general improvement of agricultural production technology, and the decline of local preference for agricultural products in various countries and regions. We use the global trade CGE model to simulate and predict the changes in the border effect of agricultural trade between China and the B\&R countries in different scenarios to explore the impact of the sustaining promotion of the $\mathrm{B} \& \mathrm{R}$ initiative on China agricultural products trade.

The existing theories and empirical studies of global trade have shown that trade cost has a significant impact on bilateral trade and the reduction of trade cost will reduce the bilateral trade barriers and lead to the reduction of border effect (Anderson and Van Wincoop, 2004; Gaurav and Mathur, 2016; Jacks et al., 2008, 2011; Tan et al., 2016; Xu et al., 2012; Yang et al., 2015). China's economic ties with the B\&R countries will get closer and trade cost will be significantly reduced with the implementation and improvement of the B\&R initiative. Therefore, we first consider the short-term impact of the decline in trade cost on border effect, changes in trade cost are reflected by $c_{i i}$ '. The economic growth and agricultural technology progress of trading partners in the medium and long term will affect the agricultural trade through policy effects such as import substitution and production effects such as agricultural output increase, thereby affecting the trade

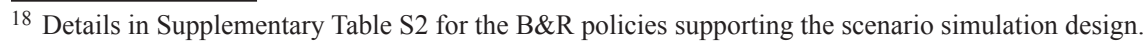


Table 8. Scenario simulations of the global trade computable general equilibrium model. ${ }^{1}$

\begin{tabular}{|c|c|c|}
\hline $\begin{array}{l}\text { Simulation } \\
\text { scheme }\end{array}$ & Hypothesis & Description \\
\hline Scenario 1 & $\begin{array}{l}\text { A total of } 20 \% \text { decline in the cost of trade } \\
\text { between China and the B\&R countries }\end{array}$ & $\begin{array}{l}\text { Economic ties between China and the B\&R } \\
\text { countries are highly strengthened after the launch } \\
\text { of the B\&R initiative and thus the induced impact } \\
\text { of the decline of bilateral trade costs on border } \\
\text { effect. }\end{array}$ \\
\hline Scenario 2 & $\begin{array}{l}\text { A total of } 20 \% \text { decline in the cost of trade } \\
\text { between China and the B\&R countries; } \\
3 \% \text { growth in the GDP of the B\&R countries. }\end{array}$ & $\begin{array}{l}\text { Under the assumption of Scenario } 1 \text {, we further } \\
\text { consider the impact of the sustained and stable } \\
\text { economic growth of the B\&R countries in a } \\
\text { certain period on border effect after the launch of } \\
\text { the B\&R initiative. }\end{array}$ \\
\hline Scenario 3 & $\begin{array}{l}\text { A total of } 20 \% \text { decline in the cost of trade } \\
\text { between China and the B\&R countries; } \\
3 \% \text { growth in the GDP of the B\&R countries; } \\
10 \% \text { progress in agricultural production } \\
\text { technology. }\end{array}$ & $\begin{array}{l}\text { Under the assumption of Scenario 2, we further } \\
\text { consider the impact of the agricultural output } \\
\text { improvement induced by the agricultural } \\
\text { technology progress among China and the B\&R } \\
\text { countries on border effect. }\end{array}$ \\
\hline Scenario 4 & $\begin{array}{l}\text { A total of } 20 \% \text { decline in the cost of trade } \\
\text { between China and the B\&R countries; } \\
3 \% \text { growth in the GDP of the B\&R countries; } \\
10 \% \text { progress in agricultural production } \\
\text { technology; } \\
5 \% \text { decline in preference for the indigenous } \\
\text { agricultural products of each country and region. }\end{array}$ & $\begin{array}{l}\text { Under the assumption of Scenario 2, we further } \\
\text { consider that as a result of the launch of the B\&R } \\
\text { initiative, China and the B\&R countries have also } \\
\text { opened their agricultural product markets and } \\
\text { reduced their preference for local agricultural } \\
\text { products, which has an impact on border effect. }\end{array}$ \\
\hline
\end{tabular}

${ }^{1}$ More details in Supplementary Table S2 for the B\&R policies supporting the scenario simulation design; GDP = gross domestic product.

border effect (Evans, 2003; Feenstra et al., 1998; Jacks et al., 2011; Yang et al., 2010, 2015). Therefore, the long-term economic growth and agricultural technology progress are included in the scenario simulations, they can be reflected by the changes in the GDP value $y_{j}$ in Equation 12 and output measurement parameter $A_{i t}$ in the first stage production function, respectively. The local preference of agricultural products refers to the fact that consumers are highly inclined to consume locally produced agricultural products due to cost, cultural customs, tastes, and other reasons, the possible impact of local preference on bilateral trade border effect has been fully discussed in existing studies (Anderson and Van Wincoop, 2003; Furtan and Van Melle, 2004; Gong et al., 2012; Whalley and Xin, 2009). Therefore, this study considers the impact of the local preference for agricultural products in long-term simulations to examine its impact on the border effect. Local preference is expressed by share parameter $\sigma_{i t i}$, in the second-stage utility function of the demand module of the CGE model. Table 9 reports the prediction results of four scenario simulations on the basis of the actual data in 2015 .

The results of the four scenario simulations are presented in Table 9. The border effect between China and the B\&R countries has significantly declined compared with that in 2015, under the assumption of Scenario 1: the bilateral trade cost has decreased by $20 \%$, which reduces the overall bilateral effect of China by nearly half. The bilateral effects of Northeastern and Northern China have the largest decline (approximately 50 to $60 \%$ ). By contrast, the bilateral effect of Western China has the smallest decline (approximately 36.7\%). Unilateral effect has also largely declined, and except Southeastern Coastal China, the decline in export border of China's domestic regions is less than that in import border. The simulation results show that the trade cost between China and the B\&R countries falls rapidly with the launch of a series of policies after 2015, leading to the additional decline of trade barriers which is reflected in the huge reduction of the border 
Table 9. Border effect of agricultural trade between China and the Belt and Road countries under scenario simulations. ${ }^{1,2}$

\begin{tabular}{|c|c|c|c|c|c|c|c|}
\hline & & \multirow{2}{*}{\multicolumn{2}{|c|}{ Bilateral effect }} & \multicolumn{4}{|c|}{ Unilateral effect } \\
\hline & & & & \multicolumn{2}{|c|}{ Export border } & \multicolumn{2}{|c|}{ Import border } \\
\hline & & $\begin{array}{l}\text { Border } \\
\text { effect }\end{array}$ & $\begin{array}{l}\text { Variation } \\
(\%)\end{array}$ & $\begin{array}{l}\text { Border } \\
\text { effect }\end{array}$ & $\begin{array}{l}\text { Variation } \\
(\%)\end{array}$ & $\begin{array}{l}\text { Border } \\
\text { effect }\end{array}$ & $\begin{array}{l}\text { Variation } \\
(\%)\end{array}$ \\
\hline \multirow[t]{6}{*}{ Scenario 1} & China & 5.7572 & -0.4888 & 5.6182 & -0.6290 & 3.3974 & -0.3486 \\
\hline & Northeastern China & 8.0344 & -0.5271 & 5.3103 & -0.8225 & 4.8748 & -0.2316 \\
\hline & Northern China & 3.0065 & -0.6135 & 1.0692 & -0.8666 & 11.524 & -0.3604 \\
\hline & Southeastern China & 1.7488 & -0.4562 & 0.1806 & -0.4419 & 0.5021 & -0.4705 \\
\hline & Central China & 45.567 & -0.4800 & 25.817 & -0.5128 & 109.63 & -0.4473 \\
\hline & Western China & 164.09 & -0.3673 & 44.061 & -0.5014 & 399.97 & -0.2333 \\
\hline \multirow[t]{6}{*}{ Scenario 2} & China & 6.9054 & -0.3869 & 7.6680 & -0.4937 & 3.7549 & -0.2801 \\
\hline & Northeastern China & 9.6419 & -0.4325 & 10.377 & -0.6533 & 5.0018 & -0.2117 \\
\hline & Northern China & 3.5954 & -0.5384 & 1.3316 & -0.8338 & 13.640 & -0.2430 \\
\hline & Southeastern China & 1.7497 & -0.4557 & 0.1816 & -0.4391 & 0.5004 & -0.4727 \\
\hline & Central China & 62.372 & -0.2883 & 36.841 & -0.3048 & 144.43 & -0.2718 \\
\hline & Western China & 202.42 & -0.2194 & 67.373 & -0.2376 & 416.72 & -0.2012 \\
\hline \multirow[t]{6}{*}{ Scenario 3} & China & 4.7443 & -0.5788 & 3.2720 & -0.7839 & 3.2673 & -0.3736 \\
\hline & Northeastern China & 7.8729 & -0.5366 & 5.7481 & -0.8079 & 4.6617 & -0.2653 \\
\hline & Northern China & 2.5243 & -0.6755 & 2.3860 & -0.7023 & 12.562 & -0.3028 \\
\hline & Southeastern China & 1.4697 & -0.5430 & 0.1180 & -0.6354 & 0.5216 & -0.4506 \\
\hline & Central China & 33.732 & -0.6151 & 10.136 & -0.8087 & 114.75 & -0.4215 \\
\hline & Western China & 123.53 & -0.5236 & 33.618 & -0.6195 & 298.56 & -0.4277 \\
\hline \multirow[t]{6}{*}{ Scenario 4} & China & 3.8501 & -0.6581 & 2.3306 & -0.8461 & 2.7633 & -0.4702 \\
\hline & Northeastern China & 7.0261 & -0.5868 & 5.8031 & -0.8061 & 4.0135 & -0.3675 \\
\hline & Northern China & 1.9965 & -0.7433 & 1.8840 & -0.7649 & 11.235 & -0.3764 \\
\hline & Southeastern China & 1.3658 & -0.5753 & 0.0892 & -0.7244 & 0.5444 & -0.4263 \\
\hline & Central China & 26.334 & -0.6995 & 8.3522 & -0.8424 & 87.942 & -0.5566 \\
\hline & Western China & 81.481 & -0.6858 & 22.320 & -0.7474 & 196.07 & -0.6242 \\
\hline
\end{tabular}

effect, and the reduction of border effect shows regional differences: the decline in border effect of Northern and Northeastern China is the largest, followed by that of Central China and Southeastern Coastal China. the decline in border effect of Western China is smallest. The simulation results also indicate that with the implementation of the B\&R initiative and the decline in trade cost, the agricultural trade deficit between China and the B\&R countries still exists, however, the gap narrows down, indicating that the China regional import dependence of agricultural products is reduced.

The border effect still declined while considering the decline of bilateral trade costs as well as the future economic growth of the B\&R countries, under the assumption of Scenario 2. However, the magnitude of the decrease of the border effect is smaller than that in Scenario 1: the overall bilateral effect has decreased by $38.7 \%$. The decline in bilateral effects of China's domestic regions was less than 55\%, and that of Western China has only decreased by $21.9 \%$; the unilateral effects also show similar results. This situation suggests that the economic growth of the B\&R countries can increase bilateral trade barriers in a certain extent, 
thereby increasing the border effect. The reason may be due to the improvement in the economic growth of the B\&R countries' national income levels resulting in additional domestic consumption and investment, another reason is $\mathrm{B} \& \mathrm{R}$ countries make additional trade diversion to their neighboring countries outside China. However, the specific reason still needs in depth investigation.

Agricultural technology progress, along with other hypotheses, has decreased the overall border effect of China by approximately $57.9 \%$, under the assumption of Scenario 3. The decrease rate is $9 \%$ more than that under the assumption of Scenario 1. The border effects of China's domestic regions also decreased by more than 50\%. The gap of border effects of all regions except Southeastern Coastal China has increasingly narrowed, and the results for export and import border are basically the same. These simulation results suggest that the continued ascension of the agricultural production technology improves the structure and efficiency of agricultural production, to an extent promoting the advantage of agricultural production export while reducing the production cost. As a result, the B\&R countries can achieve an efficient circulation of products through trade and the agricultural trade regional inequality can be reduced., The decline of the local agricultural product preference, along with other hypotheses, leads to more than $60 \%$ of continuous decline of the border effect of China and to that the China's entire export border is smaller than import border, under the assumption of Scenario $4^{19}$.

In sum, the border effect of agricultural trade between China and the B\&R countries shows a clear decline compared with that in 2015 under all four scenario simulations. The conclusion is that with the implementation and improvement of the B\&R initiative in the future, the decline of trade costs and local preferences, and the agricultural technology progress will highly reduce the border effect, agricultural trade activities will tend to be highly active, and a continued growth of agricultural trade will exist between China and the $\mathrm{B} \& \mathrm{R}$ countries. The contribution of the four scenario simulations to the decline of border effect is sorted in descending order: Scenario $4(-65.8 \%)>$ Scenario $3(-57.9 \%)>$ Scenario $1(-48.9 \%)>$ Scenario 2 $(-38.7 \%)$. The contribution of the changes in factors affecting the border effect to the reduction of bilateral effect can be sorted in descending order: decrease of trade cost $(-48.9 \%)>$ decrease of local agricultural product preference $(-16.9 \%)>$ agricultural production technology progress $(-9 \%)$. However, the economic growth of trade partners increases the border effect by $10.2 \%$. The simulation results for the border effect of China's domestic regions are quite different, reflecting the reality that the inter-regional trade development is unbalanced: the trade development of Southeast Coastal China is better than that of Central China and Western China. However, the gap in trade development is gradually narrowing after the implementation of the $\mathrm{B} \& \mathrm{R}$ initiative.

\section{Conclusions and policy implications}

In this study, we have constructed a global trade CGE model using the input-output table data in 2002, 2007, 2010, and 2015 to measure the border effect of the bilateral trade of agricultural products between China and the B\&R countries, thereby measuring the impact of the B\&R initiative on China's agricultural trade from 2010 to 2015. In addition, we have designed a simulation analysis under four different scenarios to determine the long-term impact of the B\&R initiative on China's agricultural trade. This analysis is based on the implementation and improvement of the B\&R initiative, the development of the world economy, the agricultural technology progress, and the inter-regional changes in demand for agricultural products.

Our findings suggest that the border effect of agricultural products trade between China and the B\&R countries has continued to decline from 2002 and 2015. After the B\&R initiative was proposed in 2013, the border effect in 2015 has decreased by $20.9 \%$ compared to that in 2010. Considering the change in the regional trade market and trade policies from 2010 to 2015, we find that the B\&R initiative probably reduced the trade barriers and promoted the bilateral agricultural trade between China and the B\&R countries to some extent. Moreover, there are different changes in border effect between China's domestic regions and between

\footnotetext{
$\overline{19}$ We provided the actual trade data from 2016 to 2018 to support our simulation results (Supplementary Figure S1).
} 
unilateral and bilateral border: the decline of border effect in China's costal area is larger than that in inland area, and the decline in import border is larger than that in export border. The results of scenario simulations reveal that the decline of trade costs and local preferences, and the agricultural technology progress will highly reduce the border effect with the implementation and improvement of the B\&R initiative in the future. There will be a brisk agricultural trade between China and the B\&R countries, and the bilateral trade volume will continue to grow. The gap in trade development among China's domestic regions will gradually narrow.

We can obtain the following policy implications based on the above conclusions:

1. Trade cost is one of the most important factors hindering the bilateral agricultural trade. With the implementation and improvement of the B\&R initiative, China should implement policies reducing border effect for agricultural trade between China and the B\&R countries, and strengthen cooperation in improving transportation capacity, standardizing custom clearance procedures and establishing agricultural standardization system to further reduce bilateral trade costs and promote the sustainable development of the bilateral agricultural trade.

2. Agricultural technology is another important factor influencing bilateral agricultural trade. Progress in agricultural technology can effectively reduce the border effect for agricultural trade between China and the B\&R countries. Thus, the Chinese government should increase R\&D investment in the agricultural sector to promote agricultural product production technology advancement and industrial structure upgrading, thereby reducing trade barriers and promoting the bilateral agricultural trade.

3. Agricultural products local preference is also an important factor influencing bilateral agricultural trade. China should improve the quality and image of Chinese agricultural products by cultivating well-known agricultural product brands and improving the construction of agricultural product quality inspection system to increase the preference of the B\&R countries for China's agricultural products, thus promoting the development of the bilateral trade.

4. The differences in border effect between China's domestic regions restrict the bilateral agricultural trade between China and the B\&R countries. China should promote the regional division and cooperation of agricultural production, packaging, and transportation to make full use of the comparative advantages of agricultural production in domestic regions, thus improving the international competitiveness of the dominant agricultural products in domestic regions and contributing to the growth of bilateral agricultural trade.

This paper first systematically and comprehensively investigated the border effect of agricultural trade between China and the B\&R countries, depicted the changes in border effect before and after the implementation of the $\mathrm{B} \& \mathrm{R}$ initiative, and pertinently carried out the predictive analysis, not only enriching the research on agricultural trade barriers and border effects, but also effectively complementing the latest literature on the policy impact of the $\mathrm{B} \& \mathrm{R}$ initiative ${ }^{20}$. In addition, the policy implications based on the research results are of great significance to promote the growth in bilateral agricultural trade between China and the B\&R countries and the development of agricultural firms. However, admittedly, this paper has the following limitations: (1) the input-output table covers only a few years, which leads to the lack of long-term continuous dynamic effect study; (2) the international situation in the B\&R region is complicated and the scenario simulation needs to be improved; (3) lack of the causal identification and mechanism analysis for the policy effect of the B\&R initiative. We will further examine regional trade and its dynamic changes under complex scenarios on the basis of data perfection and consider more identification strategies applying quasi-natural experiment to conduct the research in the future.

\footnotetext{
${ }^{20}$ Since there is no other literature studying the border effect between China and the B\&R countries, we have compared this study with other studies about border effect and agricultural trade, between China and some B\&R countries in Supplementary Table S2 and S3.
} 


\section{Supplementary material}

Supplementary material can be found online at https://doi.org/10.22434/IFAMR2019.0115 Specific trade policies supporting the Belt and Road initiative.

Figure S1. The agricultural trade value between China and the Belt and Road countries.

Table S1. Details of the policy for the Belt and Road initiative related to scenario hypotheses.

Table S2. Comparison of literatures on measuring border effects.

Table S3. Comparison of literatures around agricultural trade between China and Belt and Road countries.

\section{Acknowledgements}

This paper won the Best Paper Award at IFAMA 2019 World Conference, we thank the IFAMA 2019 World Conference's reviewers and the audience for their suggestions, and we thank the Professor Songqing Jin and Professor Wei Xu for their helpful comments and advice.

\section{References}

Anderson, J.E. and E. Van Wincoop. 2003. Gravity with gravitas: a solution to the border puzzle. American Economic Review 93(1): 170-192. https://doi.org/10.1257/000282803321455214

Anderson, J.E. and E. Van Wincoop. 2004. Trade costs. Journal of Economic Literature 42(3): 691-751. https://doi.org/10.1257/0022051042177649

Armington, P. 1969. A theory of demand for products distinguished by place of production. International Monetary Fund Staff Papers 16(1): 159-178. https://doi.org/10.2307/3866403

Baier, S.L. and J.H. Bergstrand. 2001. The growth of world trade: tariffs, transport costs, and income similarity. Journal of International Economics 53(1): 1-27. https://doi.org/10.1016/s0022-1996(00)00060-x

Balistreri, E.J. and R.H. Hillberry. 2007. Structural estimation and the border puzzle. Journal of International Economics 72(2): 451-463. https://doi.org/10.1016/j.jinteco.2007.01.001

Chen, J., B. Abula and T. Chen. 2014. Research on agricultural trade pattern between China and five Central Asian countries. Journal of International Trade (4): 78-89. https://doi.org/10.13510/j.cnki. jit.2014.04.008

Chen, R., V. Hartarska and N.L.W. Wilson. 2018. The causal impact of HACCP on seafood imports in the U.S.: an application of difference-in-differences within the gravity model. Food Policy 79: 166-178. https://doi.org/10.1016/j.foodpol.2018.07.003

Chinese Academy of Social Science. 2016. Blue book of industrialization: the Belt and Road national industrialization process report. Social Science Academic Press, Beijing, China.

Disdier, A. and S. Marette. 2010. The combination of gravity and welfare approaches for evaluating nontariff measures. American Journal of Agricultural Economics 92(3): 713-726. https://doi.org/10.1093/ ajae/aaq026

Disdier, A., L. Fontagné and M. Mimouni. 2008. The impact of regulations on agricultural trade: evidence from the SPS and TBT agreements. American Journal of Agricultural Economics 90(2): 336-350. https://doi.org/10.1111/j.1467-8276.2007.01127.x

Evans, C.L. 2003. The economic significance of national border effects. American Economic Review 93(4): 1291-1312. https://doi.org/10.1257/000282803769206304

Evans, C.L. 2006. Border effects and the availability of domestic products abroad. Canadian Journal of Economics 39(1): 211-246. https://doi.org/10.1111/j.0008-4085.2006.00345.x

Fan, Z., R. Zhang and X. Liu. 2016. China's outward FDI efficiency along the Belt and Road. China Agricultural Economic Review 8(3): 455-479. https://doi.org/10.1108/CAER-11-2015-0158

Feenstra, R.C. 1998. Integration of trade and disintegration of production in the global economy. Journal of Economic Perspectives 12(4): 31-50. https://doi.org/10.1257/jep.12.4.31

Feenstra, R.C. 2002. Border effects and the gravity equation: consistent methods for estimation. Scottish Journal of Political Economy 49(5): 491-506. https://doi.org/10.1111/1467-9485.00244 
Furtan, W.H. and B.M. Van Melle. 2004. Canada's agricultural trade in North America: do national borders matter? Review of Agricultural Economics 26(3): 317-331. https://doi.org/10.1111/j.14679353.2004.00182.x

Gaurav, A. and S.K. Mathur. 2016. Determinants of trade costs and trade growth accounting between India and the European Union during 1995-2010. World Economy 39(9): 1399-1413. https://doi. org/10.1111/twec. 12317

Gong, T.Y. and W. Wang. 2014. The influence of preference difference on the border effect of China-ASEAN agricultural products trade. Journal of Agrotechnical Economics 6: 110-119. https://doi.org/10.13246/j. cnki.jae.2014.06.013

Gong, T.Y., X. Xin and W.Q. Pan. 2012. The impact of trade barriers on China-ASEAN agricultural products trade - based on the measurement and decomposition of border effect. Chinese Rural Economy 2: 64-74.

Han, Y., X.F. Luo and J.H. Zou. 2015. Trade cooperation competitiveness and complementarities of China and West Asia under the background of silk road economic belt and maritime silk road strategy. World Economy Studies 3: 89-98. https://doi.org/10.13516/j.cnki.wes.2015.03.010

He, M., N.N. Zhang and Z.Q. Huang. 2016. Analysis on trade competition and complementarity of agricultural products between China and 'The Belt and Road' countries. Issues in Agricultural Economy 11: 5160. https://doi.org/10.13246/j.cnki.iae.2016.11.006

Head, K. and J. Ries. 2001. Increasing returns versus national product differentiation as an explanation for the pattern of US-Canada trade. American Economic Review 91(4): 858-876. https://doi.org/10.1257/ aer.91.4.858

Helliwell, J.F. and G. Verdier. 2001. Measuring internal trade distances: a new method applied to estimate provincial border effects in Canada. Canadian Journal of Economics 34(4): 1024-1041. https://doi. org/10.1111/0008-4085.00111

Henson, S. and R. Loader. 2001. Barriers to agricultural exports from developing countries: the role of sanitary and phytosanitary requirements. World Development 29(1): 85-102. https://doi.org/10.1016/ S0305-750X(00)00085-1

Hillberry, R.H. 2002. Aggregation bias, compositional change, and the border effect. Canadian Journal of Economics 35(3): 517-530. https://doi.org/10.1111/1540-5982.00143

Huang, J., C. Liu and Z.C. Feng. 2018. Dual margin of China's agricultural products export growth in the Belt and Road region and its determinants. Journal of China Agricultural University 23(12): 187199. DOI: $10.11841 /$ j.issn.1007-4333.2018.12.22

Huang, Y.P. 2016. Understanding China's belt \& road initiative: motivation, framework and assessment. China Economic Review 40: 314-321. https://doi.org/10.1016/j.chieco.2016.07.007

Jacks, D.S., C.M. Meissner and D. Novy. 2008. Trade costs, 1870-2000. American Economic Review 98(2): 529-534. https://doi.org/10.1257/aer.98.2.529

Jacks, D.S., C.M. Meissner and D. Novy. 2011. Trade booms, trade busts, and trade costs. Journal of International Economics 83(2): 185-201. https://doi.org/10.1016/j.jinteco.2010.10.008

Jia, W., T.Y. Gong and F. Qin. 2017. The impact of trade costs on the growth of agricultural trade in different regions of China. Chinese Rural Economy 4: 59-74.

Lai, M.Y. and J.C. Li. 2007. Tariff reduction and exemption of the agricultural import from Asian and its impact on China's micro economy and industry - an analysis of the computable general equilibrium model. Contemporary Finance \& Economics 269(4): 98-104.

Liu, X.Y. and X. Xian. 2011. Transportation uncertainty and international trade. Transport Policy 18(1): 156-162. https://doi.org/10.1016/j.tranpol.2010.07.005

Liu, X.Y., J. Whalley and X. Xin. 2010. Non-tradable goods and the border effect puzzle. Economic Modelling 27(5): 909-914. https://doi.org/10.1016/j.econmod.2010.05.016

Lv, L.L. 2006. Similarity analysis of agricultural products export between China and ASEAN. Word Economy Studies 1: 45-49. https://doi.org/10.13516/j.cnki.wes.2006.01.006

Mccallum, J. 1995. National borders matter: Canada-U.S. regional trade patterns. American Economic Review 85(3): 615-623. https://doi.org/10.2753/PET1061-1991380390 
Obstfeld, M. and K. Rogoff. 2000. The six major puzzles in international macroeconomics: is there a common cause? Nber Macroeconomics Annual 15(1): 339-390. https://doi.org/10.1086/654423

Olper, A. and V. Raimondi. 2008. Agricultural market integration in the OECD: a gravity-border effect approach. Food Policy 33: 165-175. https://doi.org/10.1016/j.foodpol.2007.06.003

Otsuki, T., J.S. Wilson and M. Sewadeh. 2001a. Saving two in a billion: quantifying the trade effect of European food safety standards on African exports. Food Policy 26: 495-514. https://doi.org/10.1016/ S0306-9192(01)00018-5

Otsuki, T., J.S. Wilson and M. Sewadeh. 2001b. What price precaution? European harmonization of aflatoxin regulations and African groundnut exports. European Review of Agricultural Economics 28(2): 263283. https://doi.org/10.1093/erae/28.3.263

Qiu, H.G., J. Yang and J.K. Huang. 2007. The impact of the China-ASEAN free trade area on China's agricultural international trade and its regional development in agriculture. Management World 9: 56-61. https://doi.org/10.19744/j.cnki.11-1235/f.2007.09.007

Rong, J. and C. Yang. 2006. An empirical analysis of agricultural products 'competitiveness and complementarities between China and ASEAN countries. Journal of International Trade 8: 66-71. https://doi.org/10.13510/j.cnki.jit.2006.08.009

Song, S.S. 2014. Expanding foreign agricultural cooperation under the 'Belt and Road' strategy. Journal of International Economics Cooperation 9: 63-66.

State Information Center. 2005. Multi-regional input-output model for China. Social Science Academic Press, Beijing, China.

Sun, C.R., N. Zhang and Y.Y. Liu. 2017. The 'Belt and Road' initiative and China's trade growth with countries along the route. Journal of International Trade 2: 83-96. https://doi.org/10.13510/j.cnki. jit.2017.02.008

Sun, Z.L. and X.D. Li. 2013. Agricultural product trade development between China and India upon economic globalization: an empirical analysis based on trade complementarities, trade competitiveness and growth potentiality. Journal of International Trade 12: 68-78. https://doi.org/10.13510/j.cnki. jit.2013.12.007

Sun, Z.L. and X.D. Li. 2016. The current situation of agricultural products trade between China and the 'Belt and Road' countries and the prospect of agricultural economic and trade cooperation. Intertrade 11: 38-42. https://doi.org/10.14114/j.cnki.itrade.2016.11.010

Tan, J.R., X.L. Tong and X.C. Tu. 2016. Analysis of the extensive margins of export growth of 31 Chinese provinces and determining factors. Journal of International Trade 1:38-49. https://doi.org/10.13510/j. cnki.jit.2016.01.004

Whalley, J. and X. Xin. 2009. Home and regional biases and border effects in Armington type models. Economic Modelling 26(2): 309-319. https://doi.org/10.1016/j.econmod.2008.07.013

Wilson, J.S. and T. Otsuki. 2004. To spray or not to spray: pesticides, banana exports, and food safety. Food Policy 29: 131-146. https://doi.org/10.1016/j.foodpol.2004.02.003

Winchester, N., M. Rau, C. Götz, B. Larue, T. Otsuki, K. Shutes, C. Wieck, H. Burnquist, M.J.P.D. Souza and R.N.D. Faria. 2012. The impact of regulatory heterogeneity on agri-food trade. World Economy 35(8): 973-993. https://doi.org/10.1111/j.1467-9701.2012.01457.x

Xu, T.S., Z.M. Li, Y.F. Tu and C.L. Yu. 2012. China's agricultural product trade cost measurement. Chinese Rural Economy 3: 14-24.

Yang, J., J. Huang, J.J. Hong and W.L. Dong. 2015. Analysis of impacts of trade facilitation on China's economy. Journal of International Trade 9: 156-166. https://doi.org/10.13510/j.cnki.jit.2015.09.014

Yang, X., L.P. Wu and R.L. Xu. 2010. The potential impact of the US-South Korea free trade agreement on China-South Korea agricultural trade. Chinese Rural Economy 7: 12-18.

Yao, H.H. 2006. Analysis of the complementarity of agricultural products trade between China and major countries in Northeast Asia. Chinese Rural Economy 9: 81-85.

Yi, K.M. 2003. Can vertical specialization explain the growth of world trade? Journal of Political Economy 111(1): 52-102. https://doi.org/10.1086/344805 
Zhan, M.H. 2018. Research on the competitiveness and complementarities of agricultural product trade of countries along 'The Belt and Road': based on social network analysis method. Issues in Agricultural Economy 2: 103-114. https://doi.org/10.13246/j.cnki.iae.2018.02.012

Zhang, H.Q. and H.Y. Tang. 2017. A study of trade relationship between China and the areas along the belt and road initiative based on trade intensity index model. International Economics and Trade Research 3: 27-39.

Zhang, Y. H. 2009. The Effects of Foreign Demand Shocks on China's Exports. Economic Theory and Business Management (1): 69-74.

Zhou, S.D., B.C. Hu, Q. Wu and Q.F. Cui. 2006. The establishment of China-ASEAN free trade area dynamic impact analysis of regional agricultural products trade. Management World 10: 14-21. https://doi. org/10.19744/j.cnki.11-1235/f.2006.10.003 
